\title{
Alterations in ACE and ABCG2 expression levels in the testes of rats subjected to atropine-induced toxicity
}

\author{
XUE-FANG LI ${ }^{1}$, QUAN-YONG HUANG ${ }^{2}$, WEN-ZHONG YANG ${ }^{2}$, HUI-JIE WANG ${ }^{3}$ and CAN-WEI LI ${ }^{4}$ \\ ${ }^{1}$ Library of Dali University, Dali, Yunnan 671003; Departments of ${ }^{2}$ Pathology and ${ }^{3}$ Histology and Embryology, \\ School of Basic Medical Sciences; ${ }^{4}$ Department of Epidemiology and Health Statistics, \\ School of Public Health, Dali University, Dali, Yunnan 671000, P.R. China
}

Received October 7, 2015; Accepted July 20, 2016

DOI: $10.3892 / \mathrm{mmr} .2016 .5857$

\begin{abstract}
Atropine-induced damage is associated with enzyme and protein alterations. The aim of the present study was to investigate atropine-induced alterations in testicular expression levels of angiotensin-converting enzyme (ACE) and adenosine 5'-triphosphate binding cassette sub-family $\mathrm{G}$ member 2 (ABCG2) following atropine treatment. Male Wistar rats received $15 \mathrm{mg} / \mathrm{kg} /$ day atropine for 7 days; control rats received an identical volume of saline, Following treatment, the testes were harvested for immunohistochemistry and in situ hybridization to examine the protein and gene expression levels of ACE and ABCG2 by digital image analysis. ACE gene and protein expression levels were significantly reduced in the testes of atropine-treated rats, compared with control rats $(\mathrm{P}=0.0001$ and $\mathrm{P}<0.001$, respectively). In addition, $\mathrm{ABCG} 2$ gene and protein expression levels were significantly increased in the testes of atropine-treated rats, compared with control rats $(\mathrm{P}=0.0017$ and $\mathrm{P}<0.001$, respectively). Thus, the results of the present study demonstrate that testicular protein and gene expression levels of $\mathrm{ACE}$ and $\mathrm{ABCG} 2$ were altered as a result of atropine-induced toxicity in the rats. These alterations may result in abnormal testicular function, and the proteins and genes identified in the present study may be useful to elucidate the mechanisms underlying atropine-induced toxicity and provide a direction for further studies.
\end{abstract}

\section{Introduction}

Atropine sulfate is an anticholinergic drug with a wide spectrum of activity (1), exerting diverse effects on numerous

Correspondence to: Dr Quan-Yong Huang, Department of Pathology, School of Basic Medical Sciences, Dali University, Building 1F, Block D, Xiaguan Wanhua Road, Dali, Yunnan 671000, P.R. China

E-mail: hqy0726@126.com

Key words: angiotensin-converting enzyme, adenosine 5'-triphosphate binding cassette subfamily G member 2, testes, rat, atropine-induced systems. Rapid administration of atropine during resuscitation may be life-saving (2). Atropine has also been used for the treatment of anticholinesterase pesticide poisoning (3), bradycardia and associated hypotension (4). In addition, atropine may significantly slow the progression of myopia in children (5). Furthermore, atropine has been demonstrated to have a significant anti-emetic effect (6).

Although the importance of atropine in the treatment of organophosphate poisoning is generally recognized, numerous side effects of atropine have been reported, suggesting potential toxicity (7). Atropine used in dobutamine stress echocardiograms has been reported to cause morbidity (8). Atropine has been shown to be cytotoxic to human corneal epithelial cells via the induction of cell cycle arrest and death receptor-mediated mitochondrion-dependent apoptosis (9). In the heart, atropine toxicity resulted in altered expression levels of E-cadherin and serotonin (10), and in the lung, atropine decreased pulmonary gas exchange in a dose-dependent manner (11). In addition, atropine alters pulse rate, pupil diameter and salivary flow (12). The use of atropine eye drops has been reported to cause significant toxicity (13), and a dose of atropine $1 \%$ may result in pupillary mydriasis and accommodative paralysis (14). Previous studies have demonstrated that atropine is primarily involved in decreasing male fertility by inhibiting the transport of sperm and semen in rats (15). In addition, the angiotensin-converting enzyme (ACE) and adenosine 5'-triphosphate binding cassette sub-family $G$ member 2 (ABCG2) were observed to be altered in the testes in some conditions, such as selenium-induced toxicity $(16,17)$. However, the alterations in ACE and ABCG2 expression levels in the testes following atropine-induced toxicity remain to be elucidated.

The present study performed immunohistochemistry and in situ hybridization (ISH) to evaluate the expression levels of $\mathrm{ACE}$ and $\mathrm{ABCG} 2$ in the testes, and determine whether protein and gene expression levels were altered by atropine-induced toxicity.

\section{Materials and methods}

Animals and study design. A total of 16 healthy adult male Wistar rats, (age, 2 months; weight, 210-250 g; Sun Yat-sen University, Guangzhou, China), were used for the purposes 
of the present study. All animals were housed individually in stainless-steel wire-bottom cages in an air-conditioned room at a temperature of $25^{\circ} \mathrm{C}, 50 \%$ relative humidity and a $12-\mathrm{h}$ light/dark cycle. Rats had free access to standard pellet chow and water throughout the experimental period. All procedures described in the present study were approved by the ethics committee of Dali University (Dali, China).

Animals were randomly assigned to one of two groups ( $n=8$ rats/group): The atropine group, which received intraperitoneal injections of a physiological dose of $15 \mathrm{mg} / \mathrm{kg} /$ day atropine for seven days (one injection per day) and the control group, which received identical volumes of normal saline for seven days (10).

On day eight, the control and experimental animals were deeply anesthetized with $1 \%$ sodium pentobarbital, (Harbin Pharmaceutical Group, Co., Ltd., Harbin, China) and the testes were removed. The testes were harvested for histopathology, immunohistochemistry and ISH.

Histopathology. Testicular tissues were fixed in phosphate-buffered $4 \%$ formalin ( $\mathrm{pH} 7.4$ ) for $24 \mathrm{~h}$ and embedded in paraffin. Testes were sectioned $(4-\mu \mathrm{m})$ on a microtome and stained with hematoxylin and eosin. The slides were coded, and semiquantitative analysis of the sections was performed in a blinded manner by a pathologist using a light microscope. Histopathological alterations were evaluated as described previously $(18,19)$.

Immunohistochemistry. Testes were immersed in $4 \%$ formaldehyde in phosphate-buffered saline (PBS; $\mathrm{pH} 7.2$ ), embedded in paraffin and sectioned coronally $(4-\mu \mathrm{m})$ on a microtome. Sections were deparaffinized, and immersed in $0.3 \% \mathrm{H}_{2} \mathrm{O}_{2}$ in PBS for $10 \mathrm{~min}$ followed by $1 \%$ normal goat serum in PBS for $3 \mathrm{~min}$ to reduce nonspecific reactions. Primary mouse anti-ACE (dilution, 1:400; cat. no. sc-23908; Santa Cruz Biotechnology, Inc., Dallas, TX, USA) or rabbit anti-ABCG2 (dilution, 1:400; cat. no. sc-130933; Santa Cruz Biotechnology, Inc.) antibodies were added to sections and incubated overnight at $4^{\circ} \mathrm{C}$. Subsequently, sections were washed three times in PBS and incubated with biotin-conjugated goat anti-mouse and goat anti-rabbit IgG secondary antibodies (cat. nos. sc-23908 and sc-130933, respectively; dilution, 1:400; Santa Cruz Biotechnology, Inc.) for $1 \mathrm{~h}$ at room temperature. Following five washes with PBS, tissue sections were incubated for $10 \mathrm{~min}$ in streptavidin-peroxidase (horseradish peroxidase; Santa Cruz Biotechnology, Inc.) and then washed three further times with PBS. Bound antibody was visualized with diaminobenzidine (DAB), and sections were counterstained with hematoxylin according to the methods described previously (20-22). PBS was substituted for primary antibody as the negative control.

ISH. ACE and ABCG2 genes were detected using ISH kits purchased from Wuhan Boster Biological Technology, Ltd., Wuhan, China (catalog nos. MK-2335 and MK-2675, respectively). ISH was performed according to the manufacturer's instructions, with slight modifications. Briefly, slides were denatured with $70 \%$ formamide in $2 \mathrm{X}$ saline sodium citrate buffer at $65^{\circ} \mathrm{C}$ for $10 \mathrm{~min}$. The probe mixture was denatured at $65^{\circ} \mathrm{C}$, incubated at $37^{\circ} \mathrm{C}$ for $10 \mathrm{~min}$ and subsequently applied to the slides in a moist chamber. Following overnight hybridization, slides were washed with PBS for $5 \mathrm{~min}$. Positive signals were visualized with DAB and sections were counterstained with hematoxylin. The slides were dried at room temperature (23).

Image processing. Total integrated optical density (IOD), a parameter representing $\mathrm{ACE}$ and $\mathrm{ABCG} 2$ expression levels in testicular tissue, was determined using a microscope (BX41; Olympus Corporation, Tokyo, Japan), digital camera (DP-10; Olympus Corporation) and image-analysis program (MetaMorph software version 4.65; Molecular Devices, LLC, Sunnyvale, CA, USA). A total of five images were captured of each immuno- and ISH-stained section (magnification, x200) from eight rats, which were used to calculate the mean $(21,22)$.

Statistical analysis. Data are expressed as the mean \pm standard error. The total IOD of the two groups was compared using Kruskal-Wallis analysis. $\mathrm{P}<0.05$ was considered to indicate a statistically significant difference. All analyses were performed in SPSS version 12.0 (SPSS Inc., Chicago, IL, USA).

\section{Results}

Histological examination. Hematoxylin and eosin staining did not reveal any morphological differences in rat testes between the two groups (data not shown).

Expression levels of ACE protein. ACE staining was detected primarily in the tubule lumen, as fine brown granular staining. Sections were independently verified by two observers in order to confirm the results.

The photomicrographs in Fig. 1 reveal ACE staining in control (Fig. 1A) and atropine-injured (Fig. 1B) testes. Total IOD of ACE in testes from rats that had undergone atropine intoxication was significantly reduced compared with control rats $(0.0049 \pm 0.00057$ vs. $0.0063 \pm 0.00039 ; \mathrm{P}=0.0001$; Table I).

Expression levels of ABCG2 protein. ABCG2 staining was detected primarily in the tubule lumen, as fine brown granular staining.

ABCG2 staining was performed on the testes of control (Fig. 2A) and atropine-treated (Fig. 2B) rats. Total IOD of ABCG2 in testes from rats subjected to atropine intoxication was significantly increased compared with control rats $(0.0072 \pm 0.00063$ vs. $0.0059 \pm 0.00071 ; \mathrm{P}=0.0017$; Table I).

Expression levels of ACE DNA. ISH of ACE DNA was detected primarily in the tubule lumen of testicular tissue from control (Fig. 3A) and atropine-exposed (Fig. 3B) rats. Total IOD of ACE in testes from rats subjected to atropine exposure was significantly reduced compared with control rats (0.0047 \pm 0.00046 vs. $0.0062 \pm 0.00035$ : $\mathrm{P}<0.001$; Table II).

Expression levels of ABCG2 DNA. ISH of ABCG2 DNA was detected primarily in the tubule lumen of testicular tissue from control (Fig. 4A) and atropine-exposed (Fig. 4B) rats. 
Table I. IOD of ACE and ABCG2 proteins in rat testes.

\begin{tabular}{lcc}
\hline Group & ACE & ABCG2 \\
\hline Control & $0.0063 \pm 0.00039$ & $0.0059 \pm 0.00071$ \\
Atropine-treated & & \\
P-value & $0.0049 \pm 0.00057$ & $0.0072 \pm 0.00063$ \\
& 0.0001 & 0.0017 \\
\hline
\end{tabular}

$\mathrm{ACE}$ and $\mathrm{ABCG} 2$ were detected in rat testes by immunohistochemistry. IOD is a measure of staining levels. A total of five images were captured of each section. Data are expressed as the mean \pm standard error. IOD, integrated optical density; ACE, angiotensin-converting enzyme; ABCG2, adenosine 5'-triphosphate binding cassette subfamily $\mathrm{G}$ member 2 .

A

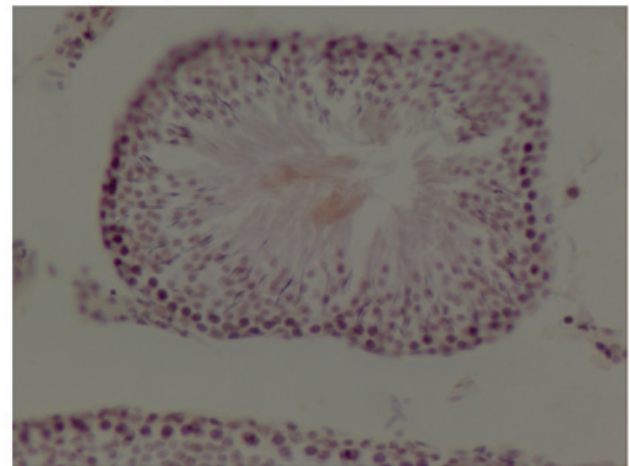

B

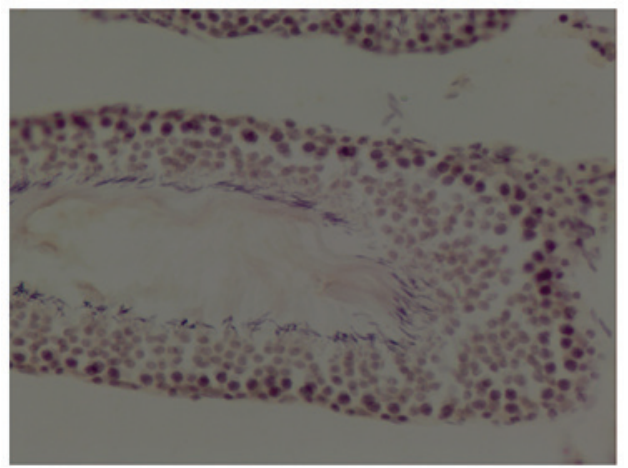

Figure 1. Effect of atropine exposure on ACE protein expression levels in rat testes. Photomicrographs reveal ACE staining in testes from (A) control and (B) atropine-treated rats. Positive immunostaining appears as brown staining. Total ACE integrated optical density in the testes of rats subjected to atropine exposure was significantly reduced compared with control rats (Table I; $\mathrm{P}<0.05)$. Magnification, $\mathrm{x} 200$. ACE, angiotensin-converting enzyme.

Total IOD of ABCG2 in testes from rats subjected to atropine exposure was significantly increased compared with control rats $(0.0070 \pm 0.00027$ vs. $0.0059 \pm 0.00016 ; \mathrm{P}<0.001$; Table II $)$.

\section{Discussion}

Although atropine is widely used, its undesirable side effects may markedly decrease quality of life.

ACE is involved in the physiology of the vasculature, blood pressure and inflammation (24). It has been demonstrated that the insertion/deletion (I/D) ACE gene polymorphism is associated with coronary restenosis (25), and may also affect blood
A

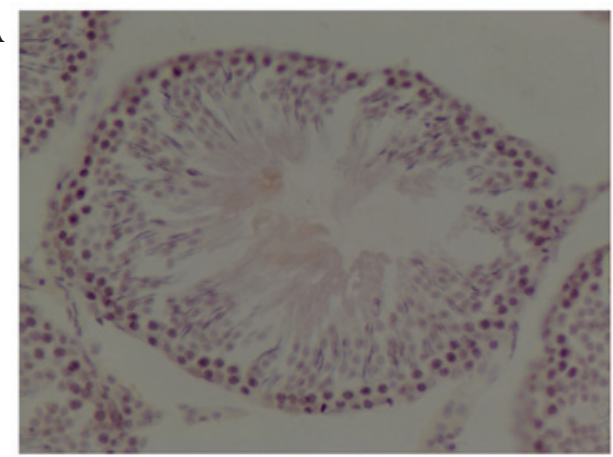

B

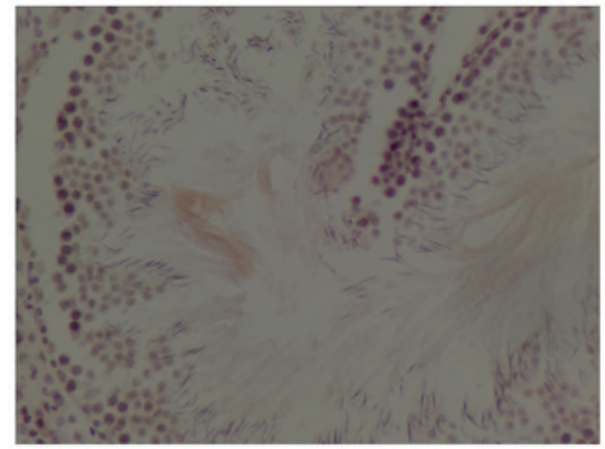

Figure 2. Effect of atropine exposure on ABCG2 protein expression levels in rat testes. Photomicrographs reveal ABCG2 staining in testes from (A) control and (B) atropine-treated rats. Positive immunostaining appears as brown staining. Total ABCG2 integrated optical density in the testes of rats subjected to atropine exposure was significantly increased compared with control rats (Table I; P<0.05). Magnification, x200. ABCG2, adenosine 5 '-triphosphate binding cassette subfamily G member 2.

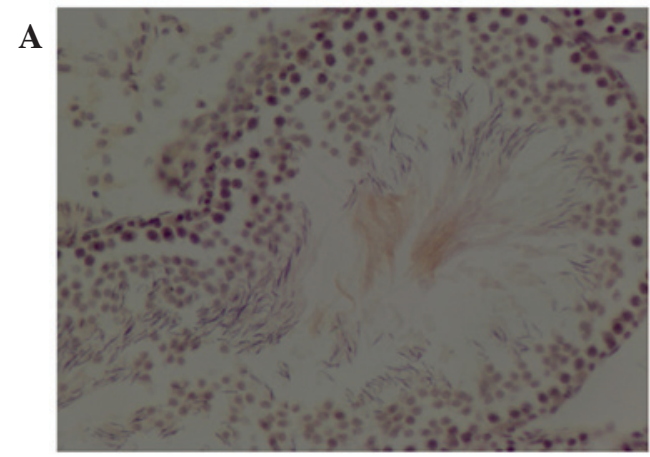

B

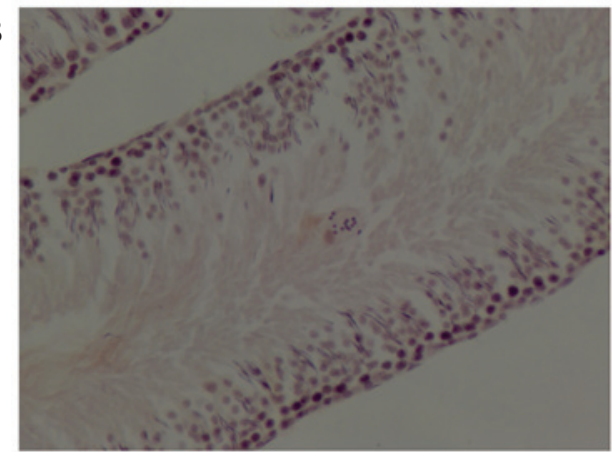

Figure 3. Effect of atropine exposure on ACE gene expression levels in rat testes. Photomicrographs reveal ISH of ACE DNA in testes from (A) control and (B) atropine-treated rats. Positive ISH staining appears as brown staining. Total ACE integrated optical density in the testes of rats subjected to atropine exposure was significantly reduced compared with control rats (Table II; P<0.05). Magnification, x200. ACE, angiotensin-converting enzyme; ISH, in situ hybridization. 
Table II. IOD of ACE and ABCG2 genes in rat testes.

\begin{tabular}{lcc}
\hline Group & ACE & ABCG2 \\
\hline Control & $0.0062 \pm 0.00035$ & $0.0059 \pm 0.00016$ \\
Atropine-treated & $0.0047 \pm 0.00046$ & $0.0070 \pm 0.00027$ \\
P-value & $<0.001$ & $<0.001$ \\
\hline
\end{tabular}

ACE and ABCG2 were detected in rat testes by in situ hybridization. IOD is a measure of staining levels. A total of five images were captured of each section. Data are expressed as the mean \pm standard error. IOD, integrated optical density; ACE, angiotensin-converting enzyme; ABCG2, adenosine 5'-triphosphate binding cassette subfamily G member 2 .
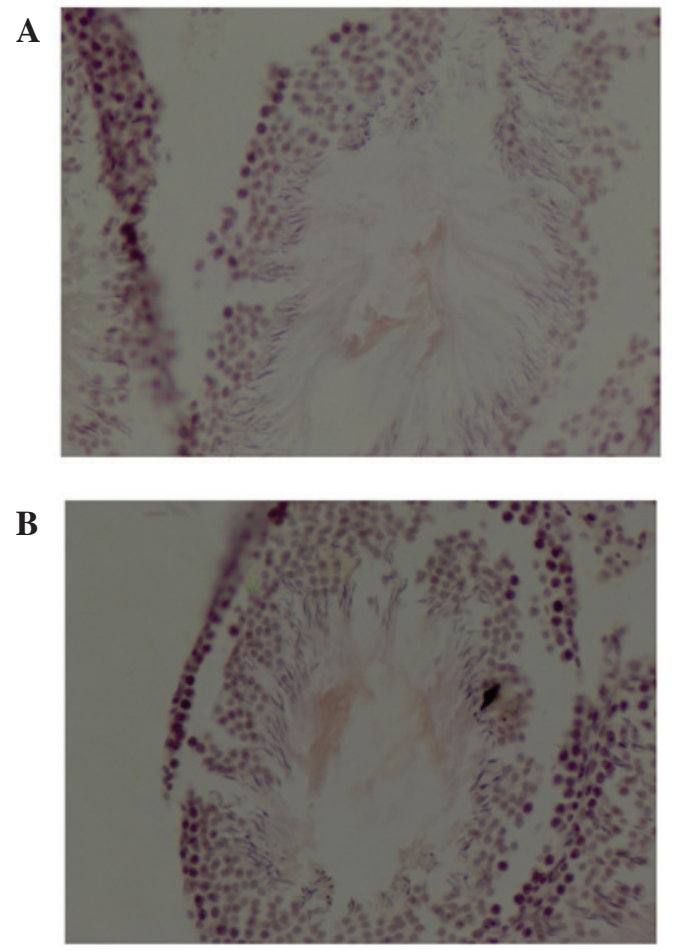

Figure 4. Effect of atropine exposure on $\mathrm{ABCG} 2$ gene expression levels in rat testes. Photomicrographs reveal ISH of ABCG2 DNA in testes from (A) control and (B) atropine-treated rats. Positive ISH staining appears as brown staining. Total ABCG2 integrated optical density in the testes of rats subjected to atropine exposure was significantly increased compared with control rats (Table II; $\mathrm{P}<0.05$ ). Magnification, $\mathrm{x} 200$. ABCG2, adenosine 5'-triphosphate binding cassette subfamily G member 2; ISH, in situ hybridization.

pressure (26) and pregnancy-induced hypertension (27). ACE is one of the factors controlling blood pressure (28). The I/D polymorphism has been associated with nitric oxide metabolite levels and systolic blood pressure in men (29), and high blood pressure at the end of pregnancy in women (30). Abnormal expression of ACE in rats resulted in inflammation, pulmonary edema and histological changes in smoke inhalation-induced lung injury (31). In humans, the I/D polymorphism of the ACE gene has been associated with the development of high altitude pulmonary edema (32).

The I/D ACE polymorphism has been demonstrated to be independent of thrombosis formation (33); however, it may be associated with osteoporosis (34), panic disorder (35) and vitiligo (36).

In the present study, the expression levels of ACE in the testes of atropine-exposed rats were significantly reduced when compared with control rats. This suggests the ACE may be associated with testicular injury (37). For example, atropine may inhibit the muscarinic acetylcholine receptor (mACh) -receptor leading to abnormal gland function (38). These alterations may influence ACE expression and the subsequent conversion of angiotensin $(39,40)$.

ABCG2 actively transports numerous endogenous and exogenous substrates across membranes (41). ABCG2 is involved in drug-resistance in cancer (42), as overexpression results in the ejection of drugs from cancer cells (43). In addition, ABCG2 overexpression promotes proliferation and suppresses apoptosis $(44,45)$. Furthermore, ABCG2 may affect the oral availability, tissue distribution and excretion of its substrates (46).

ABCG 2 has been demonstrated to be overexpressed in various solid tumors, acute myelogenous leukemia and chronic myeloid leukemia (47), and is a potential biomarker of multidrug resistance in non-small cell lung cancer (48). In addition, ABCG2 is involved in amyloid $\beta$ transport and was revealed to be significantly upregulated in Alzheimer's disease (49). ABCG2 staining may be a potential novel independent prognostic factor in colorectal cancer (50) and may be involved in hepatocellular carcinoma drug resistance (51) It has been demonstrated that ABCG2 is critical in cardiovascular and cancer pathophysiology (52). Furthermore, ABGG2 is overexpressed in acute myeloid leukemia patients with an increased risk of relapse (53).

Targeted inhibition of ABCG2 has been demonstrated to improve the efficacy of cancer therapeutics (54). Statins may downregulate ABCG2 expression and function by reducing low-density lipoprotein cholesterol levels (55). However, ABCG2 deficiency may increase oxidative stress, alter the inflammatory response in the brain and exacerbate cognitive deficits (56).

In the present study, the expression levels of ABCG2 in the testes of atropine-exposed rats were significantly increased compared with control rats. This suggests that ABCG2 may be associated with testicular injury, and influence the homeostasis of testes tissues and cells, such as the blood-testis barrier (57).

In conclusion, the results of the present study demonstrate that ACE expression levels were significantly reduced, while ABCG2 expression levels were significantly elevated, in response to atropine exposure. These alterations may be reflected in abnormal testicular function, including sperm production and motility, due to disruption of the normal homeostasis of testes tissues and cells. The proteins and genes investigated in the present study may be useful to elucidate the mechanisms underlying atropine-induced toxicity and provide directions for future studies, such as the development of therapies that activate the $\mathrm{mACh}$ receptor, as well as protect sperm production and motility during atropine treatment.

\section{Acknowledgements}

The present study was supported by grants from the National Natural Science Foundation of China (grant no. 81260466) and Dali University (grant no. KYBS201104). 


\section{References}

1. Byadagi KS, Nandibewoor ST and Chimatadar SA: Catalytic activity of ruthenium (III) on the oxidation of an anticholinergic drug-atropine sulfate monohydrate by copper (III) periodate complex in aqueous alkaline medium - decarboxylation and free radical mechanism. Acta Chim Slov 60: 617-627, 2013.

2. Konickx LA, Bingham $\mathrm{K}$ and Eddleston M: Is oxygen required before atropine administration in organophosphorus or carbamate pesticide poisoning? - A cohort study. Clin Toxicol (Phila) 52: 531-537, 2014

3. Papoutsis I, Nikolaou P, Spiliopoulou C, Pistos C, Stefanidou M and Athanaselis S: A simple and sensitive GC/MS method for the determination of atropine during therapy of anticholinesterase poisoning in serum samples. Drug Test Anal 4: 229-234, 2012.

4. Stephenson M, Wong A, Rotella JA, Crump N, Kerr F and Greene SL: Deliberate fingolimod overdose presenting with delayed hypotension and bradycardia responsive to atropine. J Med Toxicol 10: 215-218, 2014

5. Li SM, Wu SS, Kang MT, Liu Y, Jia SM, Li SY, Zhan SY, Liu LR, $\mathrm{Li} \mathrm{H}$, Chen W, et al: Atropine slows myopia progression more in Asian than white children by meta-analysis. Optom Vis Sci 91: 342-350, 2014

6. Baciarello M, Cornini A, Zasa M, Pedrona P, Scrofani G, Venuti FS and Fanelli G: Intrathecal atropine to prevent postoperative nausea and vomiting after Cesarean section: A randomized, controlled trial. Minerva Anestesiol 77: 781-788, 2011.

7. Jandrić Z, Rathor MN, Chhem-Kieth S, Adu-Gyamfi J, Mayr L, Resch C, Bado S, Švarc-Gajić J and Cannavan A: Uptake of (14) $\mathrm{C}$-atropine and/or its transformation products from soil by wheat (Triticum aestivum var Kronjet) and their translocation to shoots. J Environ Sci Health B 48: 1034-1042, 2013.

8. Wilson ME, Lee GK, Chandra A and Kane GC: Central anticholinergic syndrome following dobutamine-atropine stress echocardiography. Echocardiography 28: E205-E206, 2011

9. Tian CL, Wen Q and Fan TJ: Cytotoxicity of atropine to human corneal epithelial cells by inducing cell cycle arrest and mitochondrion-dependent apoptosis. Exp Toxicol Pathol 67: 517-524, 2015.

10. Huang QY, Li XF and Liu SP: E-cadherin and 5-HT alterations in the heart of rats having undergone atropine-induced toxicity. Mol Med Rep 5: 700-704, 2012.

11. Gaspari RJ and Paydarfar D: Pulmonary effects of intravenous atropine induce ventilation perfusion mismatch. Can J Physiol Pharmacol 92: 399-404, 2014

12. Fry JR and Burr SA: A double-blind atropine trial for active learning of autonomic function. Adv Physiol Educ 35: 438-444, 2011.

13. Stellpflug SJ, Cole JB, Isaacson BA, Lintner CP and Bilden EF Massive atropine eye drop ingestion treated with high-dose physostigmine to avoid intubation. West J Emerg Med 13: 77-79, 2012.

14. Cooper J, Eisenberg N, Schulman E and Wang FM: Maximum atropine dose without clinical signs or symptoms. Optom Vis Sci 90: 1467-1472, 2013.

15. Sato T, Ban Y, Uchida M, Gondo E, Yamamoto M, Sekiguchi Y, Sakaue A, Kemi M and Nakatsuka T: Atropine-induced inhibition of sperm and semen transport impairs fertility in male rats. J Toxicol Sci 30: 207-212, 2005.

16. Hahnova-Cygalova L, Ceckova M and Staud F: Fetoprotective activity of breast cancer resistance protein (BCRP, ABCG2): Expression and function throughout pregnancy. Drug Metab Rev 43: 53-68, 2011

17. Khalid A, Khudhair N, He H, Peng Z, Yaguang T and Guixue Z: Effects of dietary selenium supplementation on seminiferous tubules and SelW, GPx4, LHCGR and ACE expression in chicken testis. Biol Trace Elem Res 173: 202-209, 2016.

18. Helin HO, Lundin ME, Laakso M, Lundin J, Helin HJ and Isola J: Virtual microscopy in prostate histopathology: Simultaneous viewing of biopsies stained sequentially with hematoxylin and eosin and alpha-methylacyl-coenzyme A racemase/p63 immunohistochemistry. J Urol 175: 495-499, 2006.

19. De Rossi A, Rocha LB and Rossi MA: Application of fluorescence microscopy on hematoxylin and eosin-stained sections of healthy and diseased teeth and supporting structures. J Oral Pathol Med 36: 377-381, 2007.

20. Smith PS, Parkinson IH and Leong AS: Principles of ploidy analysis by static cytometry. Clin Mol Pathol 49: M104-M111, 1996.
21. Dong J, Yin H, Liu W, Wang P, Jiang Y and Chen J: Congenital iodine deficiency and hypothyroidism impair LTP and decrease C-fos and C-jun expression in rat hippocampus. Neurotoxicology 26: 417-426, 2005.

22. van Kuijk AW, Gerlag DM, Vos K, Wolbink G, de Groot M, de Rie MA, Zwinderman AH, Dijkmans BA and Tak PP: A prospective, randomised, placebo-controlled study to identify biomarkers associated with active treatment in psoriatic arthritis: Effects of adalimumab treatment on synovial tissue. Ann Rheum Dis 68: 1303-1309, 2009.

23. Seo HW, Han K, Oh Y, Kang I, Park C, Joo HE, Kim SH, Lee $\mathrm{BH}$ and Chae C: Evaluation of commercial polyclonaland monoclonal-antibody-based immunohistochemical tests for 2 genotypes of Porcine circovirus type 2 and comparison with in-situ hybridization assays. Can J Vet Res 78: 233-236, 2014.

24. Rashed L, Abdel Hay R, Mahmoud R, Hasan N, Zahra A and Fayez S: Association of Angiotensin-Converting Enzyme (ACE) gene polymorphism with inflammation and cellular cytotoxicity in vitiligo patients. PLoS One 10: e0132915, 2015.

25. Miao HW and Gong H: Association of ACE insertion or deletion polymorphisms with the risk of coronary restenosis after percutaneous coronary intervention: A meta-analysis. J Renin Angiotensin Aldosterone Syst 16: 844-850, 2015

26. Goessler KF, Cornelissen VA, de Oliveira EM, de F Mota G and Polito MD: ACE polymorphisms and the acute response of blood pressure to a walk in medicated hypertensive patients. J Renin Angiotensin Aldosterone Syst 16: 720-729, 2015.

27. Miao HW and Gong $\mathrm{H}$ : Correlation of ACE gene deletion/insertion polymorphism and risk of pregnancy-induced hypertension: A meta-analysis based on 10,236 subjects. J Renin Angiotensin Aldosterone Syst 16: 982-994, 2015.

28. Betancur-Ancona D, Dávila-Ortiz G, Chel-Guerrero LA and Torruco-Uco JG: ACE-I inhibitory activity from phaseolus lunatus and phaseolus vulgaris peptide fractions obtained by ultrafiltration. J Med Food 18: 1247-1254, 2015.

29. Avila-Vanzzini N, Posadas-Romero C, Gonzalez-Salazar Mdel C, Maass-Iturbide C, Melendez-Ramirez G, Perez-Mendez O, Del Valle-Mondragon L, Masso-Rojas F, Varela Lopez E, Herrera-Bello $\mathrm{H}$, et al: The ACE I/D polymorphism is associated with nitric oxide metabolite and blood pressure levels in healthy Mexican men. Arch Cardiol Mex 85: 105-110, 2015.

30. Reshetnikov EA, Akulova LY, Dobrodomova IS, Dvornyk VY, Polonikov AV and Churnosov MI: The insertion-deletion polymorphism of the ACE gene is associated with increased blood pressure in women at the end of pregnancy. J Renin Angiotensin Aldosterone Syst 16: 623-632, 2015.

31. Yilin Z, Yandong N and Faguang J: Role of angiotensin-converting enzyme (ACE) and ACE2 in a rat model of smoke inhalation induced acute respiratory distress syndrome. Burns 41: 1468-1477, 2015.

32. Bhagi S, Srivastava S, Tomar A, Bala SS and Sarkar S: Positive association of D allele of ACE gene with high altitude pulmonary edema in indian population. Wilderness Environ Med 26: 124-132, 2015.

33. Gorukmez O, Sag ŞO, Gorukmez Ö, Ture M, Topak A, Sahinturk S, Ozkaya G, Gulten T, Ali R and Yakut T: Association of the ACE I/D gene polymorphisms with JAK2V617F-positive polycythemia vera and essential thrombocythemia. Genet Test Mol Biomarkers 19: 303-308, 2015.

34. Cakmak B, Inanir A, Karakus N, Ates O and Yigit S: Association between the ACE gene I/D polymorphism and osteoporosis in a Turkish population. Z Rheumatol 74: 346-350, 2015.

35. Gulec-Yilmaz S, Gulec H, Dalan AB, Cetın B, Timirc1-Kahraman O, Ogut DB, Atasoy H, Dirımen GA, Gultekın GI and Isbır T: The relationship between ACE polymorphism and panic disorder. In Vivo 28: 885-889, 2014.

36. Badran DI, Nada $\mathrm{H}$ and Hassan R: Association of Angiotensin-Converting Enzyme ACE gene polymorphism with ACE activity and susceptibility to Vitiligo in Egyptian population. Genet Test Mol Biomarkers 19: 258-263, 2015.

37. Fujihara Y, Tokuhiro K, Muro Y, Kondoh G, Araki Y, Ikawa M and Okabe M: Expression of TEX101, regulated by ACE, is essential for the production of fertile mouse spermatozoa. Proc Natl Acad Sci USA 110: 8111-8116, 2013.

38. Shi CL, Täljedal IB and Mattsson MO: Effect of carbachol on regulation of the $m A C h$ receptor mRNA expression ADN insulin secretion in mouse pancreatic islets. Acta Physiol Scand 167: A18, 1999. 
39. Balyasnikova IV, Metzger R, Franke FE, Conrad N, Towbin H, Schwartz DE, Sturrock ED and Danilov SM: Epitope mapping of mAbs to denatured human testicular ACE (CD143). Tissue Antigens 72: 354-368, 2008.

40. Rushworth CA, Guy JL and Turner AJ: Residues affecting the chloride regulation and substrate selectivity of the angiotensin-converting enzymes (ACE and ACE2) identified by site-directed mutagenesis. FEBS J 275: 6033-6042, 2008.

41. Schnepf R and Zolk O: Effect of the ATP-binding cassette transporter ABCG2 on pharmacokinetics: Experimental findings and clinical implications. Expert Opin Drug Metab Toxicol 9: 287-306, 2013.

42. Erdei Z, Sarkadi B, Brózik A, Szebényi K, Várady G, Makó V, Péntek A, Orbán TI and Apáti Á: Dynamic ABCG2 expression in human embryonic stem cells provides the basis for stress response. Eur Biophys J 42: 169-179, 2013.

43. Yang B, Ma YF and Liu Y: Elevated expression of Nrf-2 and ABCG2 involved in multi-drug resistance of lung cancer SP cells. Drug Res (Stuttg) 65: 526-531, 2015.

44. Xie J, Jin B, Li DW, Shen B, Cong N, Zhang TZ and Dong P: ABCG2 regulated by MAPK pathways is associated with cancer progression in laryngeal squamous cell carcinoma. Am J Cancer Res 4: 698-709, 2014.

45. Kalalinia F, Elahian F, Mosaffa F and Behravan J: Celecoxib up regulates the expression of drug efflux transporter ABCG2 in breast cancer cell lines. Iran J Pharm Res 13: 1393-1401, 2014

46. Lecerf-Schmidt F, Peres B, Valdameri G, Gauthier C, Winter E, Payen L, Di Pietro A and Boumendjel A: ABCG2: Recent discovery of potent and highly selective inhibitors. Future Med Chem 5: 1037-1045, 2013.

47. Juvale $\mathrm{K}$ and Wiese M: Design of inhibitors of BCRP/ABCG2. Future Med Chem 7: 1521-1527, 2015.

48. Wang DS, Patel A, Shukla S, Zhang YK, Wang YJ, Kathawala RJ, Robey RW, Zhang L, Yang DH, Talele TT, et al: Icotinib antagonizes ABCG2-mediated multidrug resistance, but not the pemetrexed resistance mediated by thymidylate synthase and ABCG2. Oncotarget 5: 4529-4542, 2014.
49. Fehér Á, Juhász A, László A, Pákáski M, Kálmán J and Janka Z: Association between the ABCG2 C421A polymorphism and Alzheimer's disease. Neurosci Lett 550: 51-54, 2013.

50. Wang X, Xia B, Liang Y, Peng L, Wang Z, Zhuo J, Wang W and Jiang B: Membranous ABCG2 expression in colorectal cancer independently correlates with shortened patient survival. Cancer Biomark 13: 81-88,2013.

51. Hou H, Sun H, Lu P, Ge C, Zhang L, Li H, Zhao F, Tian H, Zhang L, Chen T, et al: Tunicamycin potentiates cisplatin anticancer efficacy through the DPAGT1/Akt/ABCG2 pathway in mouse Xenograft models of human hepatocellular carcinoma. Mol Cancer Ther 12: 2874-2884, 2013.

52. Deppe S, Ripperger A, Weiss J, Ergun S and Benndorf RA: Impact of genetic variability in the ABCG2 gene on ABCG2 expression, function, and interaction with AT1 receptor antagonist telmisartan. Biochem Biophys Res Commun 443: 1211-1217, 2014.

53. Damiani D, Tiribelli M, Geromin A, Michelutti A, Cavallin M, Sperotto A and Fanin R: ABCG2 overexpression in patients with acute myeloid leukemia: Impact on stem cell transplantation outcome. Am J Hematol 90: 784-789, 2015.

54. Lin YH, Chang HM, Chang FP, Shen CR, Liu CL, Mao WY, Lin CC, Lee HS and Shen CN: Protoporphyrin IX accumulation disrupts mitochondrial dynamics and function in ABCG2-deficient hepatocytes. FEBS Lett 587: 3202-3209, 2013.

55. To KK, Hu M and Tomlinson B: Expression and activity of ABCG2, but not ABCB1 or OATP1B1, are associated with cholesterol levels: Evidence from in vitro and in vivo experiments. Pharmacogenomics 15: 1091-1104, 2014.

56. Zeng Y, Callaghan D, Xiong H, Yang Z, Huang P and Zhang W: Abcg2 deficiency augments oxidative stress and cognitive deficits in Tg-SwDI transgenic mice. J Neurochem 122: 456-469, 2012.

57. Natarajan K, Xie Y, Baer MR and Ross DD: Role of breast cancer resistance protein (BCRP/ABCG2) in cancer drug resistance. Biochem Pharmacol 83: 1084-1103, 2012. 